\title{
STUDENTS' RESPONSES TOWARD KAHOOT APPLICATION IN INDONESIAN SUBJECT
}

\author{
Lilis Amaliah Rosdiana \\ Universitas Winaya Mukti \\ lilisamaliah87@gmail.com
}

\begin{abstract}
This article aims to describe university students' responses toward Kahoot! application in Indonesian subject. Kahoot! application is commonly played by gamers in their smartphone. However, the writer used this application as a medium of teaching Bahasa Indonesia, more specifically during the quiz. The quiz was conducted once in the session of the subtopic Ejaan Yang Disempurnakan (EYD). The research method used in this study was descriptive method, with questionnaire as the research instrument. The results show that the students were more motivated, more enthusiastic and able to manage their time to think throughout the quiz. There was no tense atmosphere, and all students seemed happy and enthusiastic in answering each question. The Students and the lecturer were able to utilize their smartphones for something they never imagined before, that was, to learn by utilizing Kahoot! application.
\end{abstract}

Keywords: students' responses, Kahoot! application, Indonesian subject

\section{PENDAHULUAN}

Dosen saat ini sudah perlu pandai dalam memilih media pembelajaran. Media pembelajaraan sudah sangat bervariatif, tak bisa lagi hanya menggunakan media yang itu-itu saja. Hal ini senada dengan yang dikatakan Ningrum (2018) bahwa seorang dosen untuk diharuskan memahami metode pembelajaran terutama berkaitan pemilihan model-model pembelajaran. Memang, pemilihan media sendiri harus disesuaikan dengan tema-tema materi yang akan dibahas di dalam kelas.

Arsyad (2014), mengungkapkan bahwa manfaat media pembelajaran di antaranya adalah memperjelas penyajian pesan dan informasi sehingga dapat memperlancar dan meningkatkan proses dan hasil belajar, meningkatkan dan mengarahkan perhatian anak sehingga dapat menimbulkan motivasi belajar yang berdampak pada hasil belajar.

Sebagai ilustrasi ketika mengadakan kuis di kelas, apabila kuis tersebut menggunakan media hanya powerpoint, mahasiswa beranggapan asal kerjakan saja, tidak ada proses berpikir kritis dan terlihat malas-malasan. Lalu mereka mengumpulkan hasil kuis tersebut. Hal inilah yang melatarbelakangi perlunya mencari media yang cocok untuk mengadakan kuis agar mahasiswa terlihat lebih bersemangat, berpikir kritis, dan berlatih memanfaatkan waktu kuis.

Hal yang lebih parah, ketika diadakan kuis, mahasiswa ada yang diam-diam mencari jawaban dengan cara browsing di internet. Oleh karena itu, daripada diam-diam membuka smartphone lebih baik memang kuisnya dengan cara menggunakan smartphone yang mereka punya. Karena ketika bertanya, adakah di antara mereka yang tidak memliki smartphone? Mereka kompak menjawab "tidak ada". Bagaimana caranya smartphone menjadi lebih berguna dalam mata kuliah Bahasa Indonesia.

Kahoot adalah suatu aplikasi game dengan dua alamat website yang berbeda yaitu https://kahoot.com/ untuk pengajar dan 
https://kahoot.it/ untuk pembelajar. Kahoot dapat diakses dan digunakan secara gratis, termasuk semua fitur-fitur yang ada di dalamnya. Aplikasi Kahoot dapat digunakan untuk beberapa bentuk asesmen di antaranya kuis online, survei, dan diskusi dimana ketiganya memiliki cara yang bermacammacam untuk dimainkan. Diperlukan koneksi internet untuk dapat memainkan game ini. Kahoot dapat dimainkan secara individu, meskipun demikian yang menjadi desain utamanya adalah permainan secara berkelompok.

Sejalan dengan hal di atas, Ibrahim dalam Rofiarti (2017) menyatakan bahwa aplikasi Kahoot adalah aplikasi online untuk membuat kuis maupun survey secara interaktif. Kahoot adalah situs di mana kita dapat membuat game custom untuk mengajarkan konsep baru atau hanya untuk bersenang-senang. Dengan Kahoot dapat diciptakan sesuatu dari permainan edukatif untuk kuis bagi mahasiswa dalam kelas atau permainan pembelajaran yang lebih menyenangkan. Kahoot dapat dimainkan menggunakan web browser, tanpa perlu masuk dengan akun dengan hanya memanfaatkan smartphone peserta atau mahasiswa.

Hal ini membuat mudah untuk memungkinkan mahasiswa untuk bergabung dalam game online dari perangkat internet yang terhubung. Ibrahim dalam Rofiarti (2017) mengatakan bahwa aplikasi Kahoot dirancang untuk pembelajaran sosial, dengan peserta didik berkumpul di sekitar layar umum. Di lingkungan kelas yang khas, ini akan menjadi SmartScreen, papan tulis interaktif, atau monitor komputer. Banyak Kahoots juga dimainkan menggunakan berbagai layar alat seperti Skype, Appear.in dan Google Hangouts.

Ketika Kahoot diluncurkan, itu akan memiliki PIN yang unik secara acak yang dihasilkan oleh sistem. Menggunakan perangkat apapun dengan web browser, mahasiswa mengunjungi situs yang didedikasikan untuk partisipasi kuis, Kahoot.it, dan masukan PIN yang unik, dan kemudian memasukkan nama panggilan sebelum diarahkan ke layar tunggu. Ketika julukan semua mahasiswa muncul di layar tunggu, dosen klik tombol Start untuk memulai kuis.

Secara umum diketahui permainan bersifat menyenangkan dan motivasi. Beberapa literatur mengungkapkan bahwasanya pembelajaran yang bersifat pendekatan permainan yang melibatkan partisipasi peserta didik dalam teknologi digital, menunjukkan keingingan yang lebih besar dalam melanjutkan proses pembelajaran berikutnya dibandingan pembelajaran bersifat konvensional. Menurut Sutirna dalam Rafnis (2018) mengatakan bahwa permainan edukatif adalah sebuah permainan yang digunakan dalam proses pembelajaran dan dalam permainan tersebut mengandung unsur mendidik atau nilai-nilai pendidikan.

Berdasarkan pemaparan di atas, artikel ini tidak lain akan mendeskripsikan respon mahasiswa terhadap aplikasi Kahoot pada mata kuliah bahasa Indonesia.

\section{METODE}

Metode penelitian yang digunakan adalah penelitian deskriptif. Penulis menggunakan instrumen penelitian berupa angket. Kuis dilakukan dalam satu kali pertemuan.Yaitu pada hari Selasa, 18 September 2018.

Penulis melakukan penelitian langsung penggunaan aplikasi Kahoot pada mahasiswa Agroteknologi semester I yang berjumlah 37 orang. Akhir pelaksanaan ini kepada objek yang menjadi penelitian dimintakan persepsinya terhadap penggunaan aplikasi Kahoot melalui angket. Jumlah angket yang disebar sebanyak 20 pernyataan. 


\section{HASIL DAN PEMBAHASAN}

Hasil penelitian ini didasarkan pada variabel peserta didik yaitu mahasiswa tentang aplikasi Kahoot yang terdiri dari indikator kemenarikan, kualitas isi, kebahasaan dan kemudahan dalam menggunakannya. Hasil persepsi angket penilaian mahasiswa terhadap aplikasi Kahoot sebagai media pembelajaran khususnya kuis didasarkan atas 20 pertanyaan dengan 5 pilihan jawaban, yakni Sangat Tidak Setuju (STS), memiliki skor 1, Tidak Setuju (TS) memiliki skor 2, Kurang Setuju (KS) memiliki skor 3, Setuju (S) memiliki skor 4, dan Sangat Setuju (SS) memiliki skor 5. Adapun pertanyaan dan skor pilihan jawabannya adalah:

1) Pernyataan tentang tampilan aplikasi Kahoot pada kuis EYD ini menarik, S mendapatkan skor 9 dan SS mendapatkan skor 28.

2) Pernyataan lebih semangat untuk belajar dengan adanya kuis EYD beraplikasi Kahoot, $\mathrm{S}$ mendapat skor 4 dan SS mendapat skor 34.

3) Pernyataan pembelajaran menggunakan aplikasi Kahoot ini menjadi tidak membosankan, S mendapat skor 6 dan SS mendapat skor 31 .

4) Pernyataan kuis dengan aplikasi Kahoot ini sangat menarik menurut saya dari segi tampilan visual (gambar, foto, video) S mendapatkan skor 4 dan SS mendapatkan skor 33.

5) Pernyataan aplikasi Kahoot ini sulit dijalankan mengingat harus diakses lewat internet, TS mendapat skor 30 dan KS mendapat 7 skor.

6) Pernyataan kuis menggunakan aplikasi Kahoot ini kurang bermanfaat bagi mahasiswa dalam Pembelajaran EYD, STS mendapat skor 21, TS mendapatkan skor 9 skor, dan KS mendapat skor 7 .

7) Pernyataan motivasi belajar mahasiswa rasanya menjadi meningkat dengan adanya kuis menggunakan aplikasi Kahoot, S mendapatkan skor 8 dan SS mendapatkan skor 29.
8) Pernyataan penggunaan aplikasi Kahoot ini membuat mahasiswa tertarik untuk mengikuti kembali kuis dengan subpokok bahasan yang lain, $\mathrm{S}$ mendapatkan skor 5, dan SS mendapat skor 32.

9) Pernyataan mahasiswa lebih suka mengerjakan soal kuis menggunakan aplikasi Kahoot daripada tertulis seperti biasa, $\mathrm{S}$ mendapat skor 2 dan SS mendapat skor 35 .

10) Pernyataan soal-soal kuis yang disajikan dalam aplikasi Kahoot mahasiswa merasa lebih sulit dipahami, TS mendapat skor 25 dan KS mendapat skor 12 .

11) Pernyataan aplikasi Kahoot sangat memudahkan mahasiswa dalam mengerjakan dan memahami soal kuis EYD, S mendapat skor 9 dan SS mendapatkan skor 28.

12) Pernyataan materi soal yang disajikan mudah dipahami, KS mendapatkan skor 6, untuk pilihan jawaban $\mathrm{S}$ mendapat skor 20, dan SS mendapat skor 11.

13) Pernyataan pada saat ujian pengambilan nilai, sangat memudahkan dengan adanya aplikasi Kahoot ini, S mendapat skor 6 dan SS mendapat skor 31.

14) Pernyataan aplikasi Kahoot ini sangat mudah diakses, S mendapat skor 27 dan SS mendapat skor 10.

15) Pernyataan aplikasi Kahoot ini mempunyai kemudahan dimengerti, baik dari segi menu maupun fasilitas (tombol), S mendapat skor 9 dan SS mendapat skor 28.

16) Pernyataan kejelasan dan kemudahan pemahaman kalimat yang digunakan dalam soal, S mendapat skor 26 dan SS mendapat skor 11.

17) Pernyataan bahasa yang digunakan dalam kuis EYD ini sederhana dan mudah dimengerti, $\mathrm{S}$ mendapat skor 7 dan SS mendapat skor 30.

18) Pernyataan simbol yang digunakan pada kuis SKB sederhana dan mudah 
dibaca, S mendapat skor 26 dan S mendapat skor 11.

19) Pernyataan materi soal yang disajikan mudah dipahami, $\mathrm{S}$ mendapat skor 6 dan SS mendapat skor 31.

20) Terakhir pernyataan tes evaluasi dapat menguji seberapa jauh pemahaman tentang materi yang sudah diajarkan diperkuliahan lewat Kuis menggunakan aplikasi Kahoot, S mendapat skor 29 dan SS mendapat skor 8.

\section{PEMBAHASAN}

Berdasarkan hasil pemaparan di atas, dapat kita lihat bahwa berdasarkan hasil persepsi penilaian peserta didik terhadap penggunaan aplikasi Kahoot ini dapat dilihat bahwa indikator ketertarikan peserta didik sebesar 89,2\% dengan kriteria "Sangat Menarik", yang berarti mahasiswa sangat tertarik untuk menggunakan aplikasi Kahoot ini sebagai kuis dalam pembelajarannya. Pembelajaran yang menyenangkan, menarik minat dan tidak membosankan mahasiswa, salah satu awal agar pembelajaran menjadi bermakna bagi mahasiswa.

Mahasiswa mengaku setelah mendapat kuis dengan Kahoot ini di antaranya mereka merasa terpacu dengan waktu yang dibatasi, adrenalin mereka tertantang seperti akan bermain Rollercoaster di taman bermain. Dengan Kahoot, mereka tidak terasa sedang diuji ataupun sedang dinilai, mereka merasa sedang mengikuti layaknya permainan di smartphone. Mereka tertantang untuk membaca cepat kemudian memilih jawaban dengan tepat.

Setelah mereka memilih jawaban kuis, mereka mendapat skor yang akan menentukan posisi peringkatnya. Dalam hal ini, saya memberikan reward kepada tiga mahasiswa teratas akan mendapat bintang di dalam catatan saya, peringkat pertama mendapat lima bintang, peringkat kedua mendapat empat bintang, lalu peringkat ketiga mendapat tiga bintang. Dengan reward seperti itu, mahasiswa semakin termotivasi untuk menjawab cepat dan tepat. Sudah pasti, suasana kelas akan heboh dan ramai pada saat pelaksanaan kuis dengan menggunakan aplikasi Kahoot ini. Karena biasanya mereka bersorak sorai ketika peringkat kelas sudah tampil di akhir kuis. Sudah barang tentu mahasiswa yang mendapat peringkat tiga teratas merasa senang gembira.

Indikator kemudahan penggunaan aplikasi Kahoot oleh mahasiswa sebesar 75,7\% dengan kriteria "Sangat Menarik", yang berarti mahasiswa merasa sangat mudah dalam menggunakan aplikasi Kahoot sebagai kuis dalam pembelajarannya. Perkembangan teknologi yang cepat menjadi bernilai, jika salah satunya mudah dan aman dalam penggunaannya.

Aplikasi Kahoot ini sangat mudah untuk digunakan siapapun, syaratnya pengguna hanya memerlukan smartphone mereka sendiri untuk mengikuti kuis ini. Mahasiswa tidak harus berat membawa buku-buku atau peralatan lain untuk persiapan kuis ini. Aplikasi Kahoot ini tidak perlu di download seperti aplikasi-aplikasi pembelajaran $e$ learning lainnya. Kahoot bisa dibuka dengan mudah hanya dengan membuka Google Chrome.

Untuk membuat kuis dalam Kahoot, dosen masuk ke https://create.kahoot.it/. Jika masih belum memiliki akun, lakukan registrasi terlebih dahulu. Dosen dapat menggunakan akun email gmail untuk melakukan registrasi. Setelah itu dosen dapat mulai membuat kuis. Dalam proses pembuatan kuis, dosen dapat menambahkan soal, altenatif jawaban, menentukan jawaban yang benar, dan pengaturan lain yang diperlukan.

Setiap kuis yang dibuat secara otomatis tersimpan pada akun Kahoot, jadi dosen dapat melihat kuis yang telah dibuat sebelumnya. Setelah kuis selesai dibuat, barulah dapat memainkan kuis di dalam kelas. Kuis yang akan dimainkan di dalam kelas diidentifikasi dengan sebuah PIN. 
PIN ini didapat secara otomatis, dosen tidak harus membuat PIN secara manual. PIN akan mucul di layar dan terbaca oleh semua orang, dosen harus mempublikasikan PIN tersebut terlebih dahulu, selanjutnya barulah mahasiswa dapat memainkan kuis baik secara individual maupun berkelompok melalui situs https://kahoot.it/dan memasukkan PIN yang telah diberikan. Selama kuis berjalan, dosen memegang kontrol penuh terhadap kuis. Dosen dapat mengatur kapan soal akan ditampilkan. Pada akhir kuis, kahoot menampilkan hasil dari kuis, dan semua mahasiswa dapat melihat skor perolehan yang dikumpulkan oleh mereka masing-masing.

Akan tetapi, ada kemudahan pasti terdapat juga kesulitan. Selain smartphone, internet juga menjadi syarat utama terlaksananya kuis Kahoot ini. Maka dari itu, sebelum melaksanakan kuis hendaknya Dosen mengecek terlebih dahulu koneksi internet di lokasi yang akan menjadi tempat pelaksanaan kuis menggunakan aplikasi Kahoot ini. Karena apabila ada mahasiswa yang tidak bisa mengakses jaringan internet, yang bersangkutan hanya bisa menjadi penonton saja selama kuis berlangsung.

Indikator kebahasaan sebesar $81 \%$ dengan kriteria "Sangat Menarik", yang berarti mahasiswa mengerti dan jelas paparan soal kuis yang ditampilkan lewat Kahoot dalam kuis EYD, meskipun dalam pembuatan soal dan jawaban kuis pada aplikasi Kahoot tatanan jumlah hurufnya terbatas.

Dalam kuis ini, dosen menyajikan 30 soal berupa pilihan ganda. Materi soal terdiri dari semua bagian EYD. Dimulai dari pemakaian huruf, penulisan kata, penggunaan tanda baca, serta penulisan unsur serapan. Di ujikan pada saat materi EYD telah diberikan secara keseluruhan. Dengan begini, dosen bisa mengetes sejauh mana kemampuan dan daya ingat mahasiswa mengenai materi EYD yang telah dipelajari.

Indikator kualitas isi sebesar 75,6\% dengan kriteria "Sangat Menarik", yang berarti mahasiswa tetap menyatakan kualitas isi soal kuis tidak berkurang yang diberikan oleh dosen dalam perkuliahan EYD dengan menggunakan aplikasi Kahoot, sehingga tidak mengurangi kompetensi rencana pembelajaran.

Dalam menggunakan aplikasi Kahoot ini, siapapun bisa menggunakannya dengan mudah. Tidak terbatas usia, tua maupun muda pasti akan bisa. Aplikasi Kahoot ini tidak membutuhkan kemampun khusus IT. Orang yang baru menggunakan internet sekalipun akan dengan mudah mengikuti tahap-tahap dalam aplikasi ini. Aplikasi ini tidak banyak fitur yang akan menyulitkan penggunanya.

Hanya saja, sekali lagi penulis katakan, aplikasi ini hanya membutuhkan smartphone dan internet. Tapi mengingat saat ini jarang sekali yang tidak punya smartphone dan jaringan internet/wifi sudah ada di manamana. Penulis rasa tidak akan sulit mengaplikasikan Kahoot ini di manapun, kapanpun, dan di semua mata kuliah.

Dari keempat indikator penilaian di atas dapat dilihat secara rata-rata persepsi mahasiswa dengan penggunaan aplikasi kuis Kahoot sebagai media pembelajaran yang berarti "Sangat Menarik" untuk diaplikasikan dan digunakan dalam perkuliahan, sehingga permasalahan kebosanan, ketidaktertarikan dalam belajar dan dilema dosen menyongsong era revolusi 4.0 dapat menggunakan aplikasi Kahoot sebagai media pembelajaran tanpa mengurangi tujuan, konten dan isi kualitas pembelajaran.

\section{SIMPULAN}

Berdasarkan hasil dan pembahasan yang telah kita bahas di atas, maka diperoleh kesimpulan bahwa mahasiswa sangat tertarik dengan adanya penggunaan aplikasi Kahoot ini sebagai kuis dalam pembelajaran Bahasa Indonesia. Ini terlihat pada respon hasil angket yang penulis sebarkan. Mereka menjawab aplikasi Kahoot ini tidak membosankan, mudah dipahami, bahasa dan 
isinya mudah dimengerti, dan tidak ada kesulitan dalam menjalankan aplikasi tersebut. Melihat hasil yang menggembirakan seperti ini, penulis beranggapan bahwa aplikasi Kahoot ini dapat digunakan dalam kuis-kuis dan pembelajaran lainnya. Di era revolusi 4.0 media pembelajaran online seperti aplikasi Kahoot ini sangat cocok diterapkan karena kita sebagai dosen/pengajar harus selalu mengikuti perkembangan kecanggihan teknologi. Mahasiswa dan dosen jadi lebih dapat memanfaatkan smartphone mereka untuk sesuatu yang belum pernah mereka banyangkan yaitu belajar dengan memanfaatkan aplikasi Kahoot ini.

\section{DAFTAR PUSTAKA}

Arsyad, Azhar. 2013. Media Pembelajaran. Jakarta: Raja Grafindo Persada.

Ningrum. 2018. Studi Penerapan Media Kuis Interaktif Berbasis Game Edukasi Kahoot! Terhadap Hasil Belajar Mahasiswa. Jurnal Ilmiah Ilmu Pendidikan STKIP Persada Sintang. Volume 9 No.1 April 2018 Hal. 22-27. Terdapat pada https://docs.google.com/viewerng/viewer?url=http://jurnal. stkippersada.ac.id/jurnal/index.php/VOX/article/viewFile/ 32/29. [Online] Diunduh 22 Juli 2018.

Official Website 'Kahoot!". 2017. kahoot.com/company/. Terdapat pada https://kahoot.com/company. [Online] Diunduh pada 13 Juli 2018.

Rafnis. 2018. Pemanfaatan Platform Kahoot Sebagai Media Pembelajaran Interaktif. Jurnal Ilmiah Teknologi Pendidikan Universitas Negeri Padang. Terdapat pada http://ejournal.unp.ac.id/index.php/e-tech/article/ view/101336 [Online] Diunduh pada 10 September 2018.

Rofiarti, F. 2017. Penggunaan Platform Kahoot! dalam Menumbuhkan Jiwa Kompetitif dan Kolaboratif Anak. Pedagogi: Jurnal Anak Usia Dini dan Pendidikan Anak Usia Dini. Volume 3 No.3b. Hal.164-172. Tersedia dalam http://ejournal.unp.ac.id/index.php/etech/article/view/101336. [Online] Diunduh pada 07 Agustus 2018. 